Article

\title{
The role of family variables in fruit and vegetable consumption in pre-school children
}

\author{
Rachel L. Goldman, Cynthia L. Radnitz, Robert E. McGrath \\ Fairleigh Dickinson University, Teaneck, NJ, USA
}

\begin{abstract}
Significance for public health
Public Health Initiatives are aimed toward prevention. One way to prevent diseases such as heart disease, cancer, and asthma is to improve nutrition through increased intake of fruit and vegetables. There have been several public health initiatives geared toward increasing fruit and vegetable intake, such as the 5 A Day program. However, intake of fruit and vegetables among children remains inadequate. Research to investigate optimal strategies for increasing fruit and vegetable intake is necessary to inform these programs and to enhance the likelihood of their effectiveness. We have demonstrated in samples that have not been well studied, specifically low income, preschoolers from predominantly minority ethnic groups, that improving availability and accessibility of fruit and vegetables, as well as parental modeling, effectively predict intake, making these important elements to consider incorporating into a public health program geared toward improving nutrition in these populations.
\end{abstract}

\begin{abstract}
Most Americans, including children, continue to eat fewer fruit and vegetables than is recommended, putting themselves at increased risk of various health conditions. The aim of this study was to evaluate the relative importance of several family environment variables (food availability and accessibility, modelling of food consumption, parenting style, and family mealtime environment) in predicting children's consumption of fruit and vegetables in a sample of pre-school children from low income, predominantly ethnic minority families. Two hundred and twenty-nine primary caregivers and their pre-school children were recruited from Head Start programmes in New York and New Jersey. Caregivers gave their consent to the study, completed a series of paper and pencil questionnaires, and had both their height and weight and their children's height and weight measured. Higher availability, accessibility, and parental modelling were associated with higher consumption of fruit and vegetables in children. Availability and Accessibility were the best predictors, but Parental Modelling significantly enhanced prediction over the other variables. Public health interventions should be geared toward helping poorer families increase the availability of fruit and vegetables in their homes, advising parents on how to make them accessible, and encouraging parents to model their consumption.
\end{abstract}

\section{Introduction}

Despite recommendations made by the US Department of Health and Human Services and the US Department of Agriculture, most Americans, including children, continue to eat fewer fruit and vegetables than is considered desirable. ${ }^{1}$ Low fruit and vegetable intake is directly associated with an increased risk of many health and medical conditions, including several chronic diseases and obesity. ${ }^{2}$ In addition, the World Health Organization attributes approximately 3 million deaths per year to diseases associated with inadequate fruit and vegetable intake. ${ }^{3}$ There is a continued need for nutritional interventions that target increasing fruit and vegetable consumption, particularly in children.

Early experiences with a diverse selection of foods play an important role in future food attitudes. ${ }^{4-6}$ Due to patterns of food acceptance that develop early in life, childhood is a time to experiment with a variety of foods to develop food preferences. ${ }^{7}$ Exposure to foods and their availability and accessibility have been shown to be essential in developing not only food acceptance but also food preferences. ${ }^{6,8-11}$ Specifically, Baranowski and colleagues found school-aged children consumed more fruit and vegetables when they were easily accessible (e.g. within reach) and already prepared to be eaten (e.g. when apples and carrots had been sliced). ${ }^{12}$ Furthermore, Scaglioni and colleagues found that a positive parental role model may be a better approach to improve a child's diet than attempts to control their diet. ${ }^{13}$

Various factors potentially contribute to the underconsumption of fruit and vegetables in children. These include: i) lack of availability and accessibility of fruit and vegetables; ${ }^{10}$ ii) parental modelling of food consumption; ${ }^{13-16}$ iii) child feeding practices, ${ }^{17,18}$ and iv) family mealtime environment. ${ }^{19-21}$

The relationship between these variables and fruit and vegetable consumption has been further studied through focus group discussions with school-aged children. These researchers found fruit and vegetables were often unavailable in low income homes and inaccessible in most homes. ${ }^{12}$ Simply having fruit and vegetables available was enough to predict higher levels of consumption for those children who preferred them..$^{22}$ For those children without fruit and vegetables in their homes, availability had to be combined with easy access before consumption levels increased. Consequently, parents can have a substantial impact on the development of child food preferences, since they primarily determine which foods are accessible and available.

A second possible explanation for low levels of fruit and vegetable consumption is lack of a parental model. A number of studies indicate similarities between parents' and children's food acceptance, preferences, consumption, and dietary behaviours, although it is not known whether the underlying mechanism of the similarities is truly modelling or something else. ${ }^{23-25}$ Children aged two to five years of age accepted a novel food more quickly, and consumed more of that food, when an adult was eating a similar food in their presence. ${ }^{14}$ While parental fruit and vegetable consumption impacts that of their children, child feeding practices (the manner in which parents attempt to modify children's eating behaviours) can also be influential. In particular, parents' feeding attitudes and practices affect the types of foods children are offered, control the timing, size, and social context of meals, and set the tone for the eating environment. ${ }^{18}$ Parents use many different strategies to ensure their children eat properly, includ- 
ing coercive and controlling approaches.$^{26}$ Research has shown that the degree of control that parents exert over their children's eating is an important influence on children's food preference and inevitably on what is consumed. ${ }^{27,28}$

Birch and colleagues have identified two forms of parental control that they termed restriction and pressure. With both forms, the intention is to improve healthy eating in children. ${ }^{18}$ Restriction refers to the parent limiting access to certain foods, while pressure to eat is an active attempt to increase consumption of healthy foods, such as fruit and vegetables. Previous research has indicated that control over the quality of the food environment should be encouraged, while strict parental control over the child's food intake should be discouraged as it is likely to have the opposite effect to what was intended..$^{26,29}$ Strict parental control has been linked to problematic eating behaviour, overconsumption of restricted foods, and limited intake of pressured foods. ${ }^{17,27,28}$ Although a number of studies have examined food-related parenting practices, few published studies have examined the relationship between child feeding practices and children's fruit and vegetable consumption.

Similarly, the family mealtime environment has been found to be related to fruit and vegetable consumption. Specifically, individuals viewing television while eating have been found to consume fewer fruit and vegetables and more high-fat foods compared to those who did not view television while eating. ${ }^{19-21}$

Low income families in particular have limited resources and this can make it difficult for them to provide their children with a healthy eating environment. Rasmussen and colleagues found low socio-economic status was associated with less frequent intake of fruit and vegetables. ${ }^{30}$ One reason for decreased fruit and vegetable consumption in low income families is the price of these foods. Produce prices have been increasing in recent years; while the cost of snack foods, which are usually less healthy, has been decreasing..$^{31}$ Researchers have suggested that this trend in food prices may explain why the rate of obesity continues to be high in individuals with lower incomes.

To summarize, several family environment variables have been identified as influencing children's food preferences and eating behaviours. However, their relative importance in predicting a child's fruit and vegetable consumption has yet to be empirically investigated, especially in low income families from ethnic minority groups with pre-school aged children. To date, research in this area has failed to identify the strongest predictor of children's fruit and vegetable intake or the specific mechanisms underlying it. Two previous studies ${ }^{30,32}$ had shown positive relationships between parent and child fruit and vegetable consumption. However, the underlying mechanism of this relationship remains unclear, as both Availability/Accessibility ${ }^{30,33}$ and Parent Modelling ${ }^{32,34}$ have been shown to be the strongest predictor in different studies. Furthermore, a more comprehensive examination has yet to be undertaken to investigate the relationship between these variables and other potential explanatory variables, such as child feeding practices and family mealtime environment.

The purpose of this study was to evaluate the relative importance of each of these variables in predicting children's fruit and vegetable intake in a sample of low income families from predominantly ethnic minority groups with pre-school aged children. Much of the previous research has examined adults or families with school-aged children, while there has been little research into this issue in pre-school children. Additionally, to the best of our knowledge, all of the research has been conducted only in English, while our research was conducted in both English and Spanish which allowed us to study a more diverse sample. By understanding which family environment variables are the best predictors, public health programmes can be crafted to specifically target those behaviours empirically shown to increase the consumption of fruit and vegetables in a low income multicultural population.

\section{Design and Methods}

\section{Participants}

Parents or primary caregivers and their pre-school children (aged 25 years) were recruited from Head Start programmes in New York and New Jersey as part of a larger study that was approved by the Fairleigh Dickinson University Institutional Review Board. All recruited caregivers whose primary language was English or Spanish were invited to participate. A total of 233 caregiver-child pairs took part in the study. Four were eliminated because their children were out of the targeted age range, so the final sample consisted of 229 caregiver-child pairs. Approximately $61 \%$ of the caregivers completed the study in English. Demographic data for caregivers and children are shown in Tables 1 and 2. We have included children's BMI data from the most recent NHANES study ${ }^{35}$ for comparison. Our study sample was made up of a numerically larger proportion of ethnic minority group participants: $81.7 \%$ African-American and Latino compared to the $56.2 \%$ of the NHANES sample. At the same time, we studied a smaller percentage of White participants (6.1\%) vs $35.2 \%$ in the NHANES sample. The mean child age was 3.89 years $(\mathrm{SD}=0.75)$. For this sample, the mean Body Mass Index (BMI) z score of the children was 0.91 (SD=1.39); 12.6\% were in the $85^{\text {th }}$ to $95^{\text {th }}$ percentile (overweight) and $22.9 \%$ were in the $95^{\text {th }}$ percentile or above (obese). Visual inspection of BMI data revealed that although the proportions of each sample who were overweight (BMI z scores between the $85^{\text {th }}$ and $95^{\text {th }}$ percentiles) were comparable, we found a greater prevalence of obese participants (BMI z score above $95^{\text {th }}$ percentile) in our sample (22.9\%) $v s$ the NHANES sample (12.1\%).

\section{Procedure}

Head Start programme groups in New York and New Jersey were contacted to solicit their participation. Caregivers of pre-school children enrolled at these sites were given the opportunity to attend a course and discussion on children's nutrition, entitled Healthy Eating, Healthy Kids, where healthy snacks and refreshments were provided. Approximately 30 presentations took place with 2-20 caregivers attending each presentation. At the presentation, caregivers were offered an opportunity to participate in this research study in return for a chance to win a food basket and a DVD player.

Informed consent was obtained from all participants and their rights were explained. In addition to a demographic questionnaire, those caregivers who agreed to participate completed a series of questionnaires prior to hearing the presentation. English and Spanish versions of all measures were available. Translation and back translation of the English versions into Spanish were made blindly and independently by native bilingual speakers. Height and weight of both caregivers and children were measured.

\section{Measures}

In several cases, single-item indicators were extracted from longer multi-item scales because they focused on constructs of interest in this study, while the parent scale addressed a more general construct. This decision is consistent with prior studies demonstrating the validity of single-item face-valid indicators when compared with multi-item alternatives. ${ }^{36,37}$

\section{Diet history questionnaire}

The 2007 version of the Diet History Questionnaire (DHQ), ${ }^{38}$ consisting of 124 items that measure both portion sizes and the frequency of intake of different types of food over the past year, was used. Two studies have demonstrated superior validity for the DHQ when com- 
pared with other food frequency questionnaires. ${ }^{39,40}$

Due to the length of the DHQ, the questionnaire was modified as follows: i) the sections assessing portion size were eliminated; ii) foods with ten or fewer calories (e.g. coffee and tea) were eliminated; iii) foods that were not usually consumed by children (e.g. alcoholic beverages) were eliminated; and iv) individual foods were combined into larger categories (e.g. apples, pears, and bananas were replaced with fruit). The modified DHQ consisted of 32 items assessing the frequency of different foods consumed. Caregivers completed it twice so they could describe both caregiver and child eating behaviours. Two questions from the child version asking caregivers how frequently their child eats fruit and vegetables were used for the purposes of the present study. The range of consumption was 0-120 times per month.

\section{The child feeding questionnaire}

The Child Feeding Questionnaire (CFQ) ${ }^{18}$ is a 31 -item self-report measure based on Costanzo and Woody's ${ }^{29}$ model that specifies how parenting practices are linked to childhood obesity. The CFQ was designed to measure child-feeding attitudes and practices, and parents' perceptions and concerns regarding obesity in their children. A confirmatory factor analysis yielded 7 factors (Restriction, Pressure to Eat, Monitoring, Perceived Responsibility, Parent Perceived Weight, Child Perceived Weight, and Parents' Concerns about Child Weight).$^{18}$ The $\mathrm{CFQ}$ is intended for use with parents of children ranging in age from 2 to 11 years. Items are completed using a 5-point Likert scale.

Coefficient alpha estimates for this sample ranged from 0.60 (Pressure to Eat) to 0.88 (Monitoring) across subscales.

\section{Family mealtime environment}

Family mealtime environment was examined using a 16-item questionnaire that was modified from one previously used in a school-based intervention study (Teens Eating for Energy and Nutrition at School, TEENS). ${ }^{19,41}$ For the current study, the questions were revised slightly from those given in the TEENS project to reflect pre-school children as opposed to adolescents. Four items assess the frequency of mealtime behaviours (e.g. eating together, having the television on during dinner) using a 3-point scale from less than 1 time per week to over 3 times per week. The remaining 12 questions ask caregivers whether they agree or disagree with statements about their family eating behaviours (e.g. We are too busy to eat together as a family most nights).

Boutelle et al. ${ }^{19}$ conducted a factor analysis that yielded a 3 -item Time scale and a 4-item Television scale. Higher scores on the Time scale indicate that the family finds more time to eat together and higher scores on the Television scale indicate that the family frequently watches television during mealtime. Coefficient alpha estimates for the current sample were 0.65 (Time) and 0.66 (Television).

\section{Parent modelling questionnaire}

Four items were used to examine the extent to which caregivers model consumption of produce. The item stem My child's (mother or father) eats in his/her presence was combined with two healthy choices (fruit or vegetables) to yield 4 items reflecting modelling of fruit and vegetable intake separately by each parent. If the mother of the child completed the questionnaire, those questions pertaining to the mother were used, while if the father completed the questionnaire those questions were used in order to obtain the total score. Parents were given five response options for each statement (e.g. at every mealsnack eaten together, at most meals/snacks eaten together).

\section{Parental dietary modelling scale}

The Parental Dietary Modelling Scale (PDMS) ${ }^{16}$ is a 6-item scale that assesses the frequency with which parents model various dietary behaviours. Each of the items assesses parental performance of a specific dietary behaviour, such as eating low-fat snacks or fruit and vegetables. To measure the frequency with which they engage in specific dietary modelling behaviour, parents select from options $1=$ never to $5=$ always .

One question from the PDMS was used for the current study: When I show my child I enjoy fruit/vegetables, helshe tries them. This question was used to assess the perceived effectiveness of parental modelling of enjoyment of fruit and vegetables on the child's eating fruit and vegetables. The range of scores was $1=$ never to $5=$ always.

\section{Accessibility of produce}

Accessibility of produce was measured using one question: Do you or your partner prepare fruit and vegetables for your child (slicing, washing, peeling)? This was modified from a similar item used by Reinaerts et $a l .{ }^{42}$ in a study that included older children, as the original item reflected the children's ability to prepare produce on their own (sometimes my child prepares his/her own fruit and sometimes I prepare it).

Table 1. Demographic information on caregivers.

\begin{tabular}{lr} 
Survey language & \\
$\quad$ Caregivers completed survey in English & $61.0 \%$ \\
Caregivers did not complete survey in English & $39.0 \%$ \\
BMI mean = 30.32 & \\
BMI $=25-29.9$ (overweight) & $28.4 \%$ \\
BMI > 30 (obese) & $45.5 \%$ \\
\hline Gender & \\
Female & $90.8 \%$ \\
Male & $9.2 \%$ \\
Biological mother & \\
Caregivers that were the biological mother & $78.6 \%$ \\
Caregivers other than biological mother & $21.4 \%$ \\
\hline Marital status & \\
$\quad$ Single & $45.9 \%$ \\
$\quad$ Married & $42.4 \%$ \\
Divorced, separated, or widowed & $11.7 \%$ \\
Level of education & \\
High school diploma or less & $45.0 \%$ \\
More education than a high school diploma & $55.0 \%$ \\
Divorced, separated, or widowed & $11.7 \%$ \\
\hline Annual household income & \\
$\quad$ Less than $\$ 20,000$ & $66.0 \%$ \\
Equal to or more than $\$ 20,000$ & $44.0 \%$ \\
\hline
\end{tabular}

Table 2. Demographic information on children.

\begin{tabular}{|c|c|c|}
\hline & $\begin{array}{l}\text { Current } \\
\text { study }\end{array}$ & $\begin{array}{c}\text { NHANES } 2010 \text { data } \\
(2-5 \text { years })^{35}\end{array}$ \\
\hline \multicolumn{3}{|l|}{ Gender } \\
\hline Female & $54.0 \%$ & $47.8 \%$ \\
\hline Male & $46.0 \%$ & $52.1 \%$ \\
\hline \multicolumn{3}{|l|}{ Ethnic group } \\
\hline Latino & $57.2 \%$ & $38.5 \%$ \\
\hline African American & $24.5 \%$ & $17.7 \%$ \\
\hline White & $6.1 \%$ & $35.2 \%$ \\
\hline Asian & $2.2 \%$ & -- \\
\hline Interracial/other & $7.8 \%$ & -- \\
\hline \multicolumn{3}{|l|}{ Child participant BMI percentile } \\
\hline $85^{\text {th }}-95^{\text {th }}$ percentile (overweight) & $12.6 \%$ & $14.6 \%$ \\
\hline $95^{\text {th }}$ percentile or above & $22.9 \%$ & $12.1 \%$ \\
\hline
\end{tabular}

The prevalence of Asian and interracial participants were not reported by Ogden et al. ${ }^{35}$ 
Parents responded using a 5-point scale ranging from always to never. Higher scores indicated greater accessibility of produce.

\section{Availability of produce}

Availability of produce was measured using two questions, one asking parents about the availability of fruit and vegetables in the home and another asking parents about the availability of fruit and vegetables that the child likes in the home. ${ }^{42}$ Items were completed on a 5point scale from always to never, and were averaged to create one availability variable. Higher scores indicated greater availability of produce. The coefficient alpha estimate for the current sample was 0.89 .

\section{Results}

Descriptive statistics for all measures may be found in Table 3. Zeroorder correlations were computed in order to determine the relative contribution of the family environment variables to children's fruit and vegetable consumption. As shown in Table 3 , availability ( $\mathrm{r}=0.26)$, accessibility $(r=0.20)$, parental modelling of fruit and vegetable consumption $(r=0.15)$, and the effectiveness of parental modelling $(r=0.17)$ were significantly related to children's fruit and vegetable intake.

Analyses were also conducted for these predictors for fruit and vegetables separately. Availability was a significant predictor of both fruit $(r=0.25, \mathrm{P}<0.01)$ and vegetable $(r=0.24, \mathrm{P}<0.01)$ intake. Positive relationships were also found for accessibility of both fruit $(r=0.19$, $\mathrm{P}<0.01)$ and vegetables $(r=0.18, \mathrm{P}<0.01)$. A significant positive relationship was found between parent modelling and vegetable consumption $(r=0.19, \mathrm{P}<0.01)$ but not fruit consumption.

A hierarchical regression analysis was conducted to assess the incremental relationship between Parental Modelling and consumption of fruit and vegetables over Availability and Accessibility. As shown in Table 4, results for Step 1 were significant: $R^{2}=0.074, F(2,222)=8.88$, $\mathrm{P}<0.001$. Availability was a significant predictor over Accessibility: $t(222)=2.78, \mathrm{P}=0.01$. But Accessibility was not a significant predictor over Availability: $t(222)=1.19, \mathrm{P}=0.235$. In Step 2, Parental Modelling did not result in a significant increment in fit over the first two predictors. To assess the incremental effect of the perceived effectiveness of Parental Modelling of fruit and vegetables on the child eating fruit and vegetables over Availability and Accessibility on children's fruit and vegetable consumption, a second hierarchical regression analysis was conducted using the effectiveness item from the PDMS (When I show my child I enjoy fruitvegetables, he/she tries them). This item was associated with a significant increment in fit $(F(1,223)=9.93, \mathrm{P}=0.01)$ and accounted for an additional $2.8 \%$ of variance in consumption.

Another analysis was conducted to evaluate whether Parental Modelling was a better predictor when restricted to primary caregivers who were biological parents. As shown in Table 5, Availability and Accessibility remained significant predictors $(F(2,190)=5.89, \mathrm{P}<0.01)$ and accounted for $5.8 \%$ of the variance. When Parental Modelling was added, the increment also achieved significance $(F(1,189)=6.88$, $\mathrm{P}=0.01$ ) and accounted for an additional $3.3 \%$ of the variance.

\section{Discussion}

As hypothesized, the availability and accessibility of fruit and vegetables, and the perceived effectiveness of parental modelling were the best predictors of children's fruit and vegetable consumption. This find ing is consistent with previous research ${ }^{12,42,43}$ examining the effects
Table 3. Descriptive statistics and correlations for children's fruit and vegetable consumption and family environment variables.

\begin{tabular}{lcc}
\hline Variable & M (SD) & $r$ with 1 \\
1. Children's fruit and vegetable consumption ${ }^{\circ}$ & $39.40(26.84)$ & --- \\
2. Availability of fruit and vegetables & $4.35(0.81)$ & $0.26^{* *}$ \\
\hline 3. Accessibility of fruit and vegetables & $4.37(0.90)$ & $0.20^{* *}$ \\
4. Parental modelling of fruit and vegetables & $3.81(0.83)$ & $0.15^{*}$ \\
\hline 5. Effectiveness of modelling & $3.89(0.63)$ & $0.17^{* *}$ \\
Family mealtime environment & & \\
6. TV & $0.00(0.79)$ & -0.05 \\
7. Time & $0.00(0.65)$ & 0.05 \\
\hline Parenting style & & \\
8. Perceived responsibility & $4.42(0.66)$ & 0.10 \\
9. Perceived parent weight & $3.16(0.37)$ & -0.12 \\
10. Perceived child weight & $3.02(0.36)$ & 0.04 \\
11. Parents' concern about child's weight & $2.56(1.32)$ & 0.02 \\
12. Restriction & $3.44(0.94)$ & 0.05 \\
13. Pressure to eat & $3.58(1.03)$ & 0.00 \\
14. Monitoring & $4.19(1.02)$ & 0.12 \\
\hline
\end{tabular}

${ }^{\circ}$ Consumption was measured in terms of frequency and ranged from 0-120 times per month; "the Parent Modelling Questionnaire was used in this analysis; \$the Parental Dietary Modelling Questionnaire was used in this analysis. ${ }^{* *} \mathrm{P}<0.01$ (two-tailed); ${ }^{*} \mathrm{P}<0.05$ (two-tailed); N varied between 225 and 229.

Table 4. Hierarchical regression predicting children's fruit and vegetable consumption from parental modelling.

\begin{tabular}{|c|c|c|c|c|}
\hline Predictors & $B$ & $S E$ & $\beta$ & $\Delta R^{2}$ \\
\hline $\begin{array}{l}\text { Step } 1^{\circ} \\
\text { Availability } \\
\text { Accessibility }\end{array}$ & $\begin{array}{l}7.03 * \\
2.70\end{array}$ & $\begin{array}{l}2.53 \\
2.26\end{array}$ & $\begin{array}{l}0.21 \\
0.09\end{array}$ & $0.07^{*}$ \\
\hline $\begin{array}{l}\text { Step } 2 \\
\text { Availability } \\
\text { Accessibility } \\
\text { Parental modelling }\end{array}$ & $\begin{array}{l}6.33^{*} \\
2.65 \\
2.84\end{array}$ & $\begin{array}{l}2.58 \\
2.26 \\
2.16\end{array}$ & $\begin{array}{l}0.19 \\
0.09 \\
0.09\end{array}$ & 0.01 \\
\hline $\begin{array}{l}\text { Step } 2 \\
\text { Availability } \\
\text { Accessibility } \\
\text { Modelling effectiveness }\end{array}$ & $\begin{array}{l}6.62 * \\
1.50 \\
5.21 *\end{array}$ & $\begin{array}{l}2.54 \\
2.27 \\
1.98\end{array}$ & $\begin{array}{l}0.20 \\
0.05 \\
0.17\end{array}$ & $0.03^{*}$ \\
\hline
\end{tabular}

${ }^{*} \mathrm{P}<0.05$. ${ }^{\circ}$ The samples were slightly different for the two Step 1 analyses but the findings were the same; "the Parent Modelling Questionnaire was used in this analysis; ${ }^{\circledR}$ the Parental Dietary Modelling Questionnaire was used in this analysis.

Table 5. Hierarchical regression predicting children's fruit and vegetable consumption from parental modelling with biological parents.

\begin{tabular}{lllll} 
Predictors & \multicolumn{1}{c}{$\boldsymbol{B}$} & $\mathrm{SE}$ & $\beta$ & $\Delta \mathbf{R}^{2}$ \\
Step 1 & & & & $0.06^{*}$ \\
$\quad$ Availability & $7.04^{*}$ & 2.79 & 0.22 & \\
$\quad$ Accessibility & 0.96 & 2.62 & 0.03 & \\
Step 2 & & & & $0.03^{*}$ \\
$\quad$ Availability & $5.86^{*}$ & 2.79 & 0.18 & \\
Accessibility & 0.44 & 2.58 & 0.02 & \\
Parental modelling & $6.35^{*}$ & 2.42 & 0.19 & \\
\hline
\end{tabular}

${ }^{*} \mathrm{P}<0.05$. The Parent Modelling Questionnaire was used in this analysis. 
of fruit and vegetable availability and accessibility on dietary behaviours. When examining fruit and vegetables separately, our findings were not consistent with past research. Reinaerts and colleagues ${ }^{42}$ examined several different variables and their contribution to the fruit and vegetable consumption of Dutch children of school age. Reinaerts et al. ${ }^{42}$ found availability predicted fruit but not vegetable consumption. A possible reason for this could be that vegetables are usually served with dinner, while fruit is typically only eaten if the child chooses to eat it (i.e. as a snack). Our results may have differed from those of Reinaerts et al..$^{42}$ due to cultural differences in eating patterns between the Netherlands and the United States. Moreover, Reinaerts and colleagues ${ }^{42}$ examined children of school age, while we studied pre-school children. With regards to parental modelling predicting fruit and vegetable consumption, our findings were also similar to past findings. Specifically, children seeing their caregivers eating fruit and vegetables was related to an increase in their own consumption of fruit and vegetables. Harper and Sanders ${ }^{15}$ found that children were more likely to try unfamiliar foods after they saw an adult consuming the food. Therefore, it is evident that parents influence their children's food intake by acting as role models and eating healthy foods in the presence of their children.

The addition of the child trying fruit and vegetables after the caregiver shows enjoyment of eating them (perceived effectiveness of parental modelling) to the availability and accessibility of fruit and vegetables improved the prediction of children's fruit and vegetable consumption. This was as expected since the parent is eating the fruit and vegetables in the child's presence and the child is trying the food while the parent is eating it. Also, the parent is not only modelling consumption, but also the enjoyment of fruit and vegetables.

It was also found that the addition of Parental Modelling (the act of eating fruit and vegetables in the presence of the child) to the Availability and Accessibility of fruit and vegetables did not improve the prediction of children's fruit and vegetable consumption over Availability and Accessibility alone. Although parents may be eating in the presence of their children, they may not be modelling the behaviour if children are not paying them any attention. This is in contrast to the perceived effectiveness of Parental Modelling, which was measured by asking parents if they agree with the statement When I show my child I enjoy fruit and vegetables, my child tries them. In the latter case, the parent is not only eating the fruit and vegetables in the child's presence, but the child is engaged in the activity and also trying the food at the same time. When examining just those primary caregivers who are biological parents, it was found that the addition of Parental Modelling to Availability and Accessibility of fruit and vegetables improved prediction of children's fruit and vegetable consumption over Availability and Accessibility alone. It is unclear whether this discrepancy in findings stems from meaningful differences in sample characteristics.

A number of limitations of the current study must be considered when examining the results. This study was cross-sectional and is limited by the use of self-report measures. All of the measures reflect the perceptions of the parent or primary caregiver who filled out the questionnaire rather than direct observation or use of monitoring over a period of time. For example, having the caregivers record their children's food intake for a week would likely be more accurate than reporting on foods they previously ate. Additionally, although the high prevalence of obese (BMI at or above $95^{\text {th }}$ percentile) children in this sample (22.9\%) is similar to the estimations made in other studies of MexicanAmerican pre-school children (23.5\%), ${ }^{44}$ it was over $10 \%$ greater than the most recent NHANES sample, ${ }^{35}$ possibly due to the larger proportion of children from an ethnic minority background that we studied. Finally, the study sample consisted of parents who themselves agreed to attend a nutrition programme and, therefore, it could be assumed that these individuals are either more interested in nutrition than those who did not attend the programme or have more time to attend a programme than other Head Start parents.

In addition, the results do not address the causal nature of the relationships between the family environment variables and children's fruit and vegetable consumption. Although many factors contribute to what an individual eats, and relationships were found to exist between certain family environment variables and fruit and vegetable consumption, a longitudinal study would allow the observation of how these variables are temporally related.

In conclusion, it was found that the Availability, Accessibility, and Parental Modelling of fruit and vegetable consumption predicted children's consumption of fruit and vegetables. Additionally, it was found that Availability and Accessibility were the best predictors. This research adds to the current literature by being one of the few studies investigating fruit and vegetable consumption in a sample of low income families with pre-school aged children predominantly from ethnic minority groups. Much of the research that has been carried out in this field examined middle-class adults and families with school-aged children. This research examined fruit and vegetable intake in preschool children a time when children are still learning and developing food preferences. Additionally, by targeting low income families from ethnic minority groups, we investigated a population with significant economic barriers to purchasing produce which is a more costly alternative to other food choices. ${ }^{31}$ Approximately $66 \%$ of participants reported an annual household income of less than $\$ 20,000$. According to national spending patterns of low income families, only $17 \%$ of their income goes towards purchasing food. ${ }^{45}$ Therefore, it can be assumed that participants did not often have produce available in the home due to the high costs. It seems likely that in more affluent families, where fruits and vegetables are almost always available, Availability and Accessibility may be weaker predictors. By understanding the family environment variables that are related to fruit and vegetable consumption, public health initiatives can be geared toward helping poorer families purchase more fruit and vegetables and make them accessible to their children. Once the fruit and vegetables are available and accessible, parents also need to model healthy eating. In order for low income families to be able to provide more fruit and vegetables, policy changes at all levels need to be made to create increased opportunities for these families to have access to healthier foods.

Correspondence: Rachel L. Goldman, Bellevue Hospital Center, 462 First Avenue, Amb. Care Clinic, 4th Floor, Room 4119, New York, NY 10016, USA. Tel. +1.212.5621558. E-mail: rachelgoldman7@gmail.com Key words: pre-school children, fruit, vegetables, accessibility, modelling. Contributions: this research was part of the dissertation presented by RLG who participated in the design of the study, data collection, analyses and interpretation, and writing the manuscript. CLR chaired the dissertation committee and was also involved in the design of the study, collection and interpretation of the data, and text revision. REM was the statistician and was involved in the design of the study, analyses, interpretation of data, and text revision.

Funding: RLG receives research funding from Covidien.

Conflict of interests: the authors declare no conflict of interests.

Received for publication:18 December 2011.

Accepted for publication: 10 April 2012.

(C) Copyright R.L. Goldman et al., 2012

Licensee PAGEPress, Italy

Journal of Public Health Research 2012; 1:e22

doi:10.4081/jphr.2012.e22

This work is licensed under a Creative Commons Attribution NonCommercial 3.0 License (CC BY-NC 3.0). 


\section{References}

1. Guenther PM, Dodd KW, Reedy J, Krebs-Smith SM. Most Americans eat much less than recommended amounts of fruits and vegetables. J Am Diet Assoc 2006;106:1371-9.

2. Bazzano LA. The high cost of not consuming fruits and vegetables. J Am Diet Assoc 2006;1364-8.

3. World Health Organization. Increasing fruit and vegetable consumption becomes a global priority. Available from: www.fao.org/english/newsroom/focus/2003/fruitveg1.htm

4. Birch LL, Marlin DW. I don't like it; I never tried it: Effects of exposure to food on two-year old children's food preferences. Appetite 1982;4:353-60.

5. Capretta PI, Petersik IT, Steward DI. Acceptance of novel flavours is increased after early experience of diverse tastes. Nature 1975;254:68991.

6. Sullivan SA, Birch, LL. Infant dietary experience and acceptance of solid foods. Pediatrics 1994;93:271-7.

7. Cashdan E. A sensitive period for learning about food. Hum Nat 1994;5:279-91.

8. Birch LL. Children's preferences for high-fat foods. Nutr Rev 1992;50: 249-55.

9. Birch LL, McPhee L, Shoba BC, et al. What kind of exposure reduces children's food neophobia? Appetite 1987;9:171-8.

10. Cooke L. The importance of exposure for healthy eating in childhood: A review. J Hum Nutr Diet 2007;20:294-301.

11. Nicklas TA, Baranowski T, Baranowski JC, et al. Family and child-care provider influences on preschool children's fruit, juice, and vegetable consumption. Nutr Rev 2001;59:224-35.

12. Baranowski T, Cullen KW, Baranowski J. Psychosocial correlates of dietary intake: advancing dietary intervention. Annu Rev Nutr 1999;19:17-40.

13. Scaglioni S, Salvioni M, Galimberti C. Influence of parental attitudes in the development of children eating behaviour. Br J Nutr 2008;99:S22S25.

14. Addessi E, Galloway AT, Visalberghi E, Birch LL. Specific social influences on the acceptance of novel foods in 2-5-year-old children. Appetite 2005;45:264-71.

15. Harper LV, Sanders KM. The effects of adults' eating on young children's acceptance of unfamiliar foods. J Exp Child Psychol 1975;20:206-14.

16. Tibbs T, Haire-Joshu D, Schechtman KB, et al. The relationship between parental modelling, eating patterns, and dietary intake among AfricanAmerican parents. J Am Diet Assoc 2001;101:535-41.

17. Birch LL, Davison KK. Family environmental factors influencing the developing behavioral controls of food intake and childhood overweight. Pediatr Clin North Am 2001;48:893-907.

18. Birch LL, Fisher JO, Grimm-Thomas K, et al. Confirmatory factor analysis of the Child Feeding Questionnaire: A measure of parental attitudes, beliefs and practices about child feeding and obesity proneness. Appetite 2001;36:201-10.

19. Boutelle KN, Birnbaum AS, Lytle LA, et al. Associations between perceived family meal environment and parent intake of fruit, vegetables and fat. J Nutr Educ Behav 2003;35:24-9.

20. Feldman S, Eisenberg ME, Neumark-Sztainer D, Story M. Associations between watching tv during family meals and dietary intake among adolescents. J Nutr Educ Behav 2007;39:257-63.

21. Matheson DM, Killen JD, Wang Y, et al. Children's food consumption during television viewing. Am J Clin Nutr 2004; 79:1088-94.

22. Cullen KW, Baranowski T, Owens E, et al. Availability, accessibility, and preferences for fruit, $100 \%$ fruit juice, and vegetables influence children's dietary behavior. Health Educ Behav 2003;30:615-26.

23. Patrick $H$, Nicklas TA. A review of family and social determinants of children's eating patterns and diet quality. J Am Coll Nutr 2005;24:83-92.

24. Skinner J, Carruth BR, Moran J, et al. Toddlers' food preferences: con- cordance with family members' preferences. J Nutr Educ Behav 1998;30:17-22.

25. Hayman LL. The Dietary Intervention Study in Children (DISC): progress and prospects for primary prevention. Prog Cardiovasc Nurs 2003;18:4-5.

26. Johnson SL, Birch LL. Parents' and children's adiposity and eating style. Pediatrics 1994;94:653-61.

27. Birch LL, Fisher, JO. Development of eating behaviours among children and adolescents. Pediatrics 1998;101:539-49.

28. Satter EM. Internal regulation and the evolution of normal growth as a basis for prevention of obesity in children. J Am Diet Assoc 1996;96: 86086.

29. Costanzo PR, Woody EZ. Domain-specific parenting styles and their impact on the child's development of particular deviance: The example of obesity proneness. J Soc Clin Psychol 1985;3:425-45.

30. Rasmussen M, Krolner R, Klepp K, et al. Determinants of fruit and vegetable consumption among children and adolescents: a review of the literature. Part I. Quantitative studies. Int J Behav Nutr Phys Act 2006;3: 22-31.

31. Monsivais P, Drewnowski A. The rising cost of low-energy-density foods. J Am Diet Assoc 2007;107:2071-6.

32. Wardle J, Carnell S, Cooke L. Parental control over feeding and fruit and vegetable consumption: How are they related? J Am Diet Assoc 2005; 105:227-32.

33. Baranowski T, Domel S, Gould R. Increasing fruit and vegetable consumption among 4 th and 5 th grade students: results from focus groups using reciprocal determinism, J Nutr Educ 1993;25:114-20.

34. Fisher JO, Mitchell DC, Smiciklas-Wright H. Parental influences on young girls' fruit and vegetable, micronutrient, and fat intakes. J Am Diet Assoc 2002;102:58-64.

35. Ogden CL, Carroll MD, Kit BK, Flegal KM. Prevalence of obesity and trends in body mass index among U.S. children and adolescents, 19992010. J Am Med Assoc 2012;307:483-90.

36. Abdel-Khalek AM. Measuring happiness with a single-item scale. Soc Behav Personal 2006;34:139-50.

37. Dollinger SJ, Malmquist D. Reliability and validity of single-item selfreports: With special relevance to college students' alcohol use, religiosity, study, and social life. J Gen Psychol 2009;136:231-41.

38. National Cancer Institute. Diet history questionnaire (DHQ). Available from: www.riskfactor.cancer.gov/DHQ

39. Subar AF, Thompson FE, Kipnis V, et al. Comparative validation of the Block, Willett, and National Cancer Institute food frequency questionnaires. The eating at America's table study. Am J Epidemiol 2001; 154:1089-99.

40. Thompson FE, Subar AF, Brown CC, et al. Cognitive research enhances accuracy of food frequency questionnaire reports: Results of an experimental validation study. J Am Diet Assoc 2002;102:212-25.

41. Lytle LA, Perry CL. Applying research and theory in program planning: An example from a nutrition education intervention. Health Promot Pract 2001;2:68-80.

42. Reinaerts E, de Nooijer J, Candel M, de Vries N. Explaining school children's fruit and vegetable consumption: The contributions of availability, accessibility, exposure, parental consumption and habit in addition to psychosocial factors. Appetite 2007;48:248-58.

43. Corwin SJ, Sargent RG, Rheaume CE, Saunders RP. Dietary behaviours among fourth graders: A social cognitive theory study approach. Am J Health Behav 1999;23:182-97.

44. Melgar-Quinonez HR, Kaiser LL. Relationship of child-feeding practices to overweight in low-income Mexican-American preschool-aged children. J Am Diet Assoc 2004;104:1110-9.

45. Busch S, Hudman J. Low-income families' spending patterns: Implications for health policy. Kaiser Commission on Medicaid and the Uninsured, 2004. 